\title{
Study of the Time-Temperature-Dependent Behaviour of PVB: Application to Laminated Glass Elements
}

F. Pelayo $^{1 *}$, M.J. Lamela-Rey ${ }^{1}$, M. Muñiz Calvente ${ }^{1}$, M. López-Aenlle ${ }^{1}$, A. Álvarez-Vázquez ${ }^{1}$ and A. Fernández-Canteli ${ }^{1}$

${ }^{1}$ Department of Construction and Manufacturing Engineering. University of Oviedo.

Campus de Viesques. 33203 Gijón. Spain

*fernandezpelayo@uniovi.es

\begin{abstract}
.
The mechanical behavior of laminated glass elements is governed by material properties of the interlayer, the Polyvinyl Butiral (PVB) being the most used interlayer material in these elements. PVB is a viscoelastic material whose mechanical properties (Young's modulus, shear modulus, etc.) depend mainly on the load application time and the temperature. Thus an adequate mechanical characterization of the PVB must be performed in order to predict the response of laminated glass elements with a good accuracy

In this work, PVB specimens were subjected to static relaxation tests and to dynamic experimental tests (frequency domain) at different temperatures from $-15^{\circ} \mathrm{C}$ to $50^{\circ} \mathrm{C}$ using a DMTA equipment. Then the curves at different temperatures were related using the William-Landel-Ferry (WLF) TimeTemperature Superposition (TTS) model to obtain the mastercurve of both the time and frequency domain Young's moduli of the PVB. Finally, a viscoelastic Prony based model was fitted to the experimental data and used, afterwards, to simulate numerically the static and dynamic behaviour of different laminated glass elements at different temperatures. The numerical simulations were compared with the static and dynamic experimental results achieving a good accuracy in both the static deflections and the natural frequencies. With respect to the damping, the discrepancies are less than $22 \%$.
\end{abstract}

Keywords: Viscoelastic; material testing; mechanical properties; shift factors; laminated glass.

\section{Introduction}

Laminated glass elements are nowadays of great interest in mechanical and structural applications due to their advantages with respect to standard monolithic glass [1,2], such as vibration and noise isolation as well as the safety improvement. This composite material consists of two or more layers of monolithic glass with one or more polymer interlayers. Although the monolithic glass presents a 
brittle non-linear behaviour [3], in the pre glass-breakage is usually considered as a linear-elastic material $[4,5]$. On the other hand, the polymer interlayers present, in general, a viscoelastic behaviour, Polyvinyl Butiral (PVB) being the most used interlayer material which is usually characterized as linear-viscoelastic [4]. The viscoelastic behaviour of the PVB governs the entire behaviour of the laminated glass so that an adequate characterization of the interlayer material must be undertaken for a proper design of laminated glass elements $[6,7,8,9]$.

A full viscoelastic analysis is recommended when a precise design of a laminated glass element is needed but it is time consuming and requires to make the calculations in finite element program [9]. In order to simplify the calculations, the mechanical behaviour of the interlayer can be considered as a linear elastic material, taking at each time its equivalent elastic modulus $E(t)[10,11,12,13,14]$, i.e. neglecting the memory effect of the viscoelasticity. This simplification is assumed when the calculations are carried out with the effective thickness concept proposed recently by [4] and extended an applied by different authors $[5,9,13,14]$. Several analytical models proposed for the calculation of laminated glass elements also consider this assumption [10, 11, 12].

As a viscoelastic material, the mechanical properties of PVB are mainly dependent of the load application time [7] and the temperature working conditions [15, 16]. Hereafter, we will simply refer to the properties of the PVB as time and temperature dependent.

This time and temperature dependence implies that a large number of assays should be carried out in order to cover all the material working conditions. However, in those so-called simply thermorheological materials [16], both variables (time and temperature) can be related through the TimeTemperature Superposition (TTS) principle $[17,18]$ so, a series of stretch time experiments at different temperatures can be shifted to a reference temperature in order to obtain a broad-band time master curve at the corresponding reference temperature (see Figure 1).

Although this principle is a valuable tool for obtaining the mechanical properties of viscoelastic materials that obey the TTS, an automatic method to shift all the curves does not exist. The shifting can be done manually, using overlapping guess algorithms or, i.e. a minimization interpolation process but, in any case, a good knowledge of the master curve construction process is required [19, 20]. A schematic description of the steps to develop a TTS fit is presented in Figure 1. 


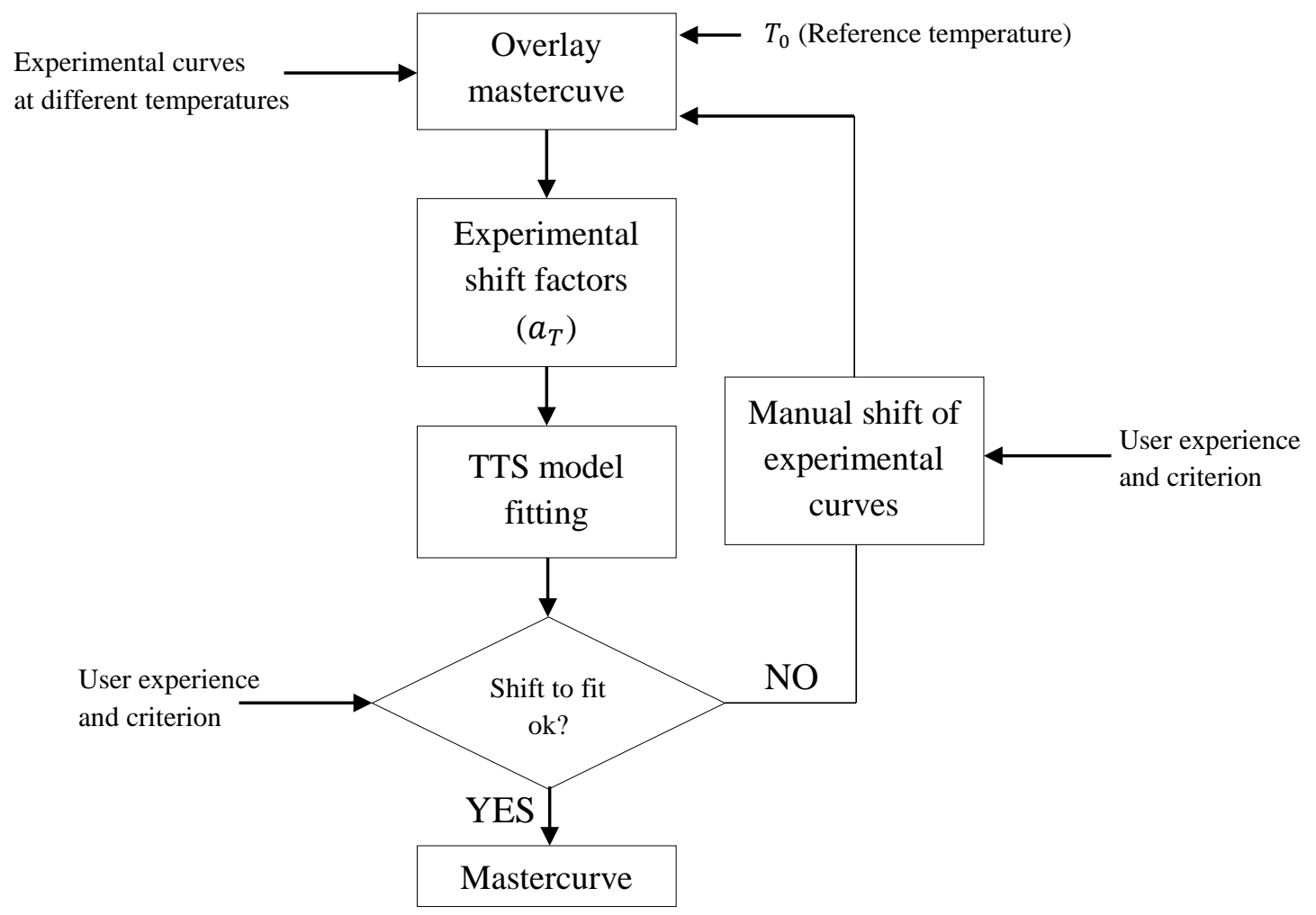

Figure 1. General steps of the time-temperature superposition method.

Several methods to determine the horizontal shift factor, $a_{T}$, that relates temperature and time, have been proposed in the literature [21, 22]. However, within the glass transition zone, the WLF [23] model is widely used in the last 6 decades since a good agreement has been observed for a large number of materials.

In the case of PVB, the WLF model has been used by different authors [4, 24]. to obtain the master curve of the material. If the master curve is obtained by a simple overlapping of the curves corresponding to different temperatures, omitting the recommendations indicated by William, Landel and Ferry [23] to fit properly the model, as well as its limitations, the fitted master curve can only represent adequately the material behaviour at one specific reference temperature. Thus if the master curve obtained by a simple overlapping is used to predict the static and/or the dynamic response of laminated glass elements at temperatures different to the reference temperature, significant large errors are expected.. Therefore, an in-depth study concerning the applicability of the WLF for constructing the master curves of PVB is needed.

In this work, the WLF model is applied to determine the master curve of PVB for the relaxation modulus, $E(t)$, as well as for the complex modulus, $E^{*}(\omega)$ of the material. The WLF constants of both master curves were compared being the results in good agreement. On the other hand, the 
relaxation $E(t)$ master curve of the PVB was fitted to a Generalized Maxwell model, using Prony series, which was used to obtain successfully the complex modulus $E(\omega)$ by analytical interconversion.

Finally, the PVB material model is applied to the analysis of laminated glass elements. Static and dynamic experiments were carried out on a laminated glass plate and a multi-layered laminated glass beam at different temperatures. The experimental results were compared with those provided by a finite element model (FEM) using the viscoelastic mechanical properties of PVB obtained in this work. A good accuracy was encountered between the numerical simulations and the experimental results.

\section{Time-Temperature Superposition Principle: The WLF Equation}

The main idea of the time-temperature superposition is to construct broadband time master curves (usually span several decades of time) from stretch time curves ( 2 or 3 decades) of the material obtained at different temperatures (see Figure 1). The principle can be applied indistinctly to the construction of any viscoelastic modulus, such as relaxation $E(t)$, creep $D(t)$ or complex $E^{*}(\omega)$. Hereafter, for the sake of simplicity the relaxation modulus $E(t)$ will be used but the methodology can be extended to the other viscoelastic functions in time or frequency domain, respectively.

To start the process of fitting a TTS model, an overlay master curve is necessary. The overlay master curve is initially obtained by overlapping the individual curves corresponding to the different tested temperatures (see Figure 2). To obtain the initial overlay master curve (see Figure 2), each individual curve at temperature $T_{i}$ has to be horizontally time-shifted to the corresponding time interval in the overlay master curve at reference temperature $T_{0}$ (see Figure 2), that is:

$$
E\left(t, T_{0}\right)_{i}=a_{T_{i}} E\left(t_{i}, T_{i}\right)
$$

where $E\left(t, T_{0}\right)_{i}$ is the time-shifted curve, $E\left(t_{i}, T_{i}\right)$ is the original curve and $a_{T_{i}}$ is the "time shift factor" (see Figure 2), hereafter, simply denoted as "shift factor". 


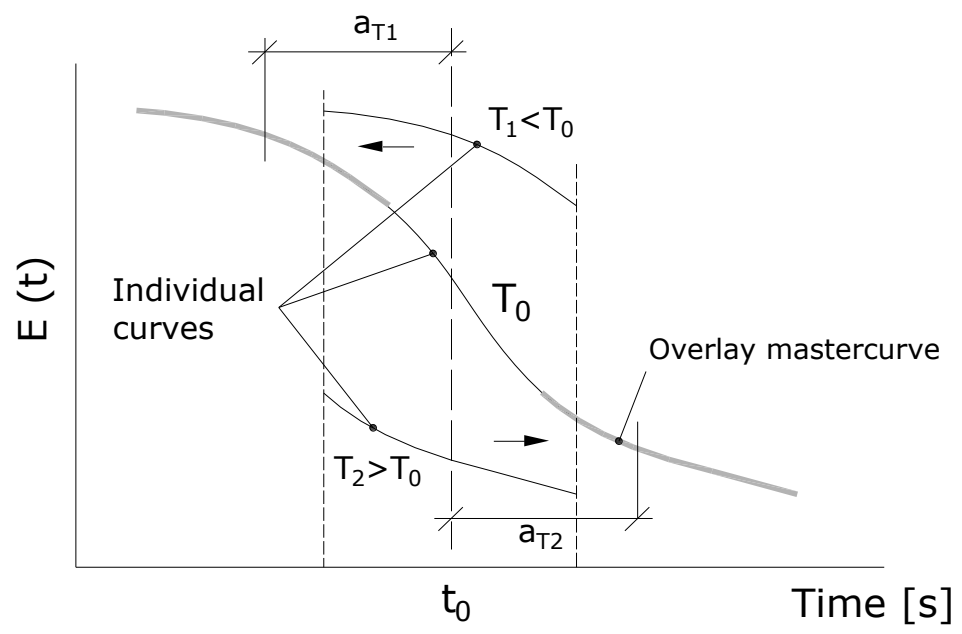

Figure 2. Schematic of the master curve creation process

In the glass transition zone, the WLF equation is widely used to obtain the horizontal shift factor, $a_{T}$, which relates the curves corresponding to two different temperatures, e.g. $T$ and $T_{0}$ and which is given by [25]:

$$
\log a_{T}=\frac{B}{2.303}\left(\frac{1}{f}-\frac{1}{f_{0}}\right)+\log \left(\frac{T_{0} \rho_{0}}{T \rho}\right)
$$

where $f_{0}$ is ratio of free to total volume of the molecules, $B$ is an empirical constant and $\rho_{0}$ is the mass density. In practice, the last term of Eq. (2) can be neglected due to the slow temperature variation of term $(T \rho)$ [25]. If it is assumed that $f$ increases linearly with temperature [25] by means of equation:

$$
f=f_{0}+\alpha_{f}\left(T-T_{0}\right)
$$

where $\alpha_{f}$ is the thermal expansion of free volume relative to total volume and if Eq. (3) is substituted in Eq. (2), the classical expression of the WLF equation is derived [25]:

$$
\log a_{T}=-\frac{C_{1}^{0}\left(T-T_{0}\right)}{\left(C_{2}^{o}+T-T_{0}\right)}
$$


where $C_{1}^{0}=B /\left(2.303 f_{0}\right)$ and $C_{2}^{0}=f_{0} / \alpha_{f}$ are empirical constants to be determined in the WLF equation fitting process for the reference temperature $T_{0}[23,25]$. The WLF equation cannot be solved directly since the two constants $C_{1}^{0}$ and $C_{2}^{0}$ must be known. Therefore, additional techniques have to be used to fit the WLF model [25]. Alternatively, the general values for constants $C_{1}^{0}$ and $C_{2}^{0}$, proposed by Willian, Landel and Ferry, may be used $[23,25]$. Once $C_{1}^{0}$ and $C_{2}^{0}$ are known for the initial reference temperature $T_{0}$, the WLF model can be used to evaluate the corresponding constants $C_{1}^{i}$ and $C_{2}^{i}$ at a different temperature, $T_{i}$, by means of the expressions:

$$
C_{1}^{i}=\frac{C_{1}^{0} C_{2}^{0}}{\left(C_{2}^{0}+T_{i}-T_{0}\right)}
$$

and

$$
C_{2}^{i}=C_{2}^{0}+T_{i}-T_{0}
$$

Therefore, the shift factors for a new master curve at reference temperature $T_{i}$ can be obtained with Eq. (4) using the new constants $C_{1}^{i}$ and $C_{2}^{i}$, calculated with Eqs. (5) and (6), respectively. Although any temperature $T_{0}$ could be considered as reference in Eq. (4) during the fitting process, William, Landel and Ferry [23] recommend the use of the glass transition temperature $\left(T_{g}\right)$ or even better, an arbitrary temperature $T_{s}$, which can be approximated by the equation [23]:

$$
T_{s} \approx T_{g}+50^{\circ} \mathrm{C}
$$

Once the master curve at temperature $T_{0}$ is created and the WLF constants are known, the whole family of mastercuves, for the range of validity of the WLF model, could be obtained (see Figure 3), so that, the time and temperature material viscoelastic modulus would be completely defined. 


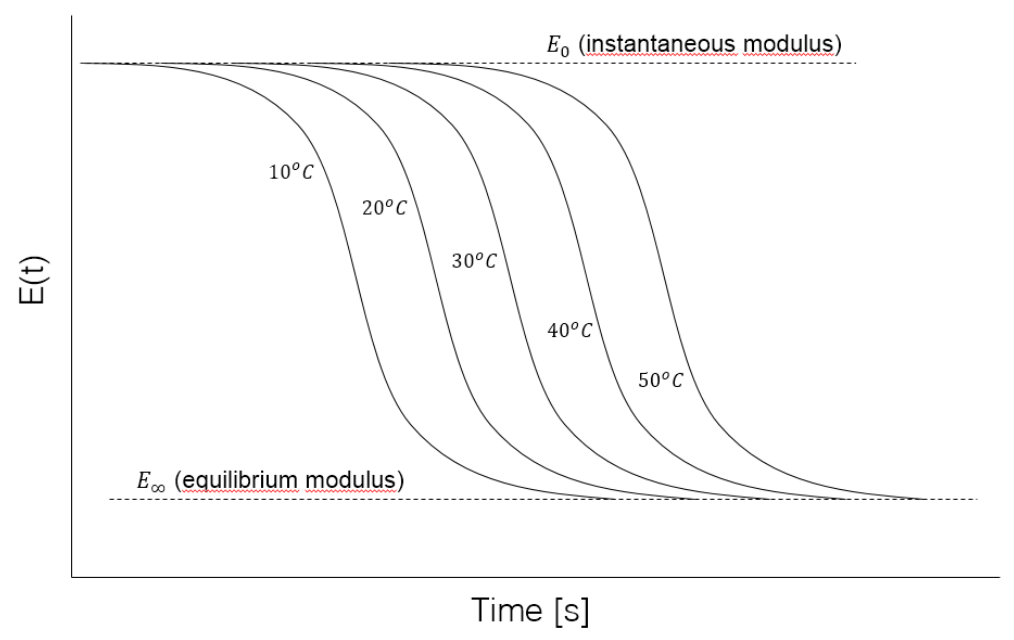

Figure 3. Example of relaxation modulus master curves at different temperatures

\section{Experimental Program}

To characterize the viscoelastic properties of the PVB, tensile relaxation tests were carried out in a DMA RSA3 by T.A. Instruments (see Figure 4). The DMA is equipped with a temperature-controlled chamber that conducts experiments over a wide range of temperatures, from $-60^{\circ} \mathrm{C}$ to $150^{\circ} \mathrm{C}$.

The material used in the experiments was standard PVB (Polyvinyl butyral) being the specimens 25 $\mathrm{mm}$ long and $5 \mathrm{~mm}$ wide with a thickness of $0.38 \mathrm{~mm}$.

In order to obtain the relaxation master curve of the material, $E(t), 15$ tensile test were conducted at different temperatures from $-15^{\circ} \mathrm{C}$ to $50^{\circ} \mathrm{C}$. A constant strain value of $\varepsilon_{0}=1 \%$ was considered in the experiments. Additionally, 10 tensile tests in the frequency range from 0.1 to $80 \mathrm{~Hz}$ were conducted at different temperatures in the range from 8 to $35^{\circ} \mathrm{C}$ to obtain the complex modulus of the material, $E(\omega)$ according to standard ASTM D5026 [26]. Finally, a temperature sweep from $25^{\circ} \mathrm{C}$ to $65^{\circ} \mathrm{C}$ at a constant frequency of $1 \mathrm{~Hz}$ and constant strain $\varepsilon_{0}=1 \%$ was carried out to obtain the glass transition temperature of the material.

The experimental curves are presented in Figs. 5 and 6 for the relaxation and complex moduli, respectively, whereas the temperature sweep curve is shown in Figure 7. 


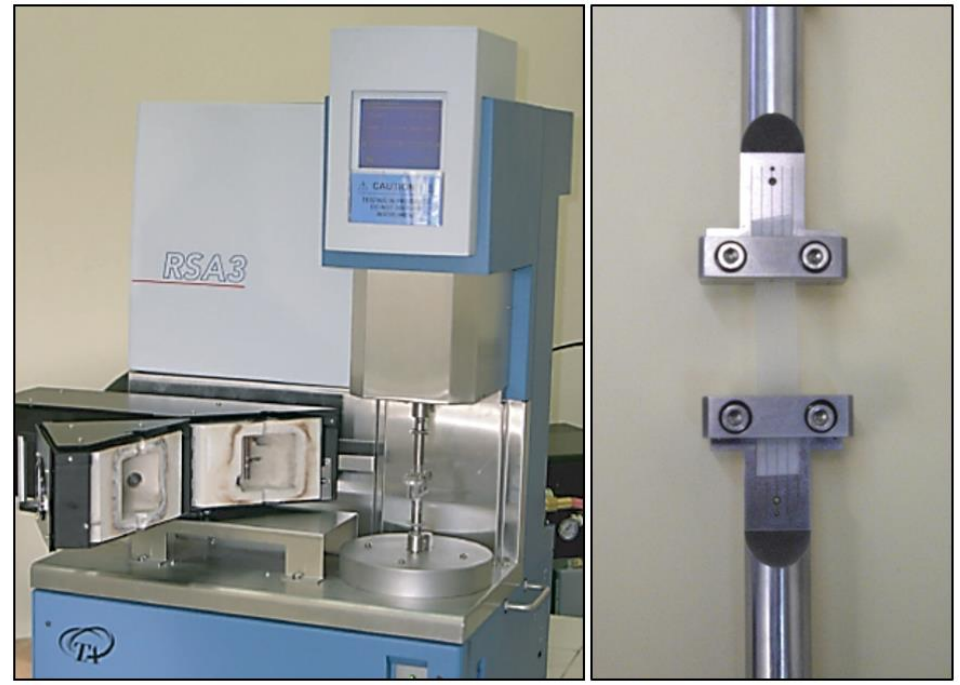

Figure 4. DMTA (RSA3. TA. Instruments) and tensile fixtures used in the experiments.

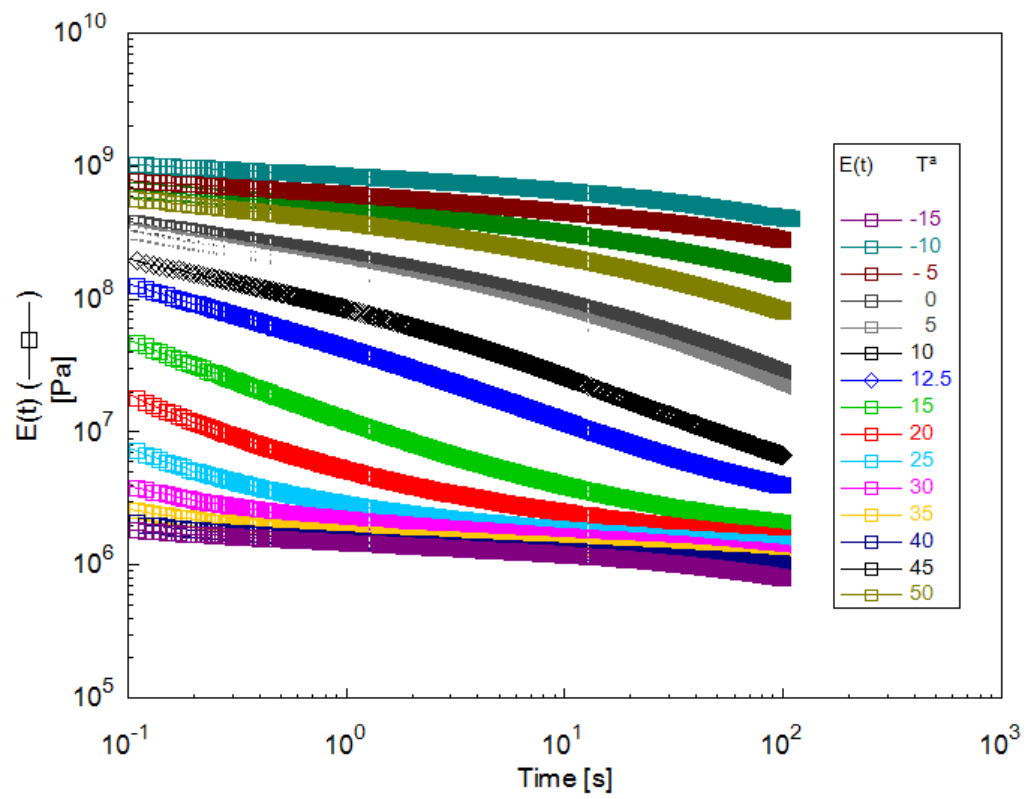

Figure 5. Relaxation curves at different temperatures for the PVB. 


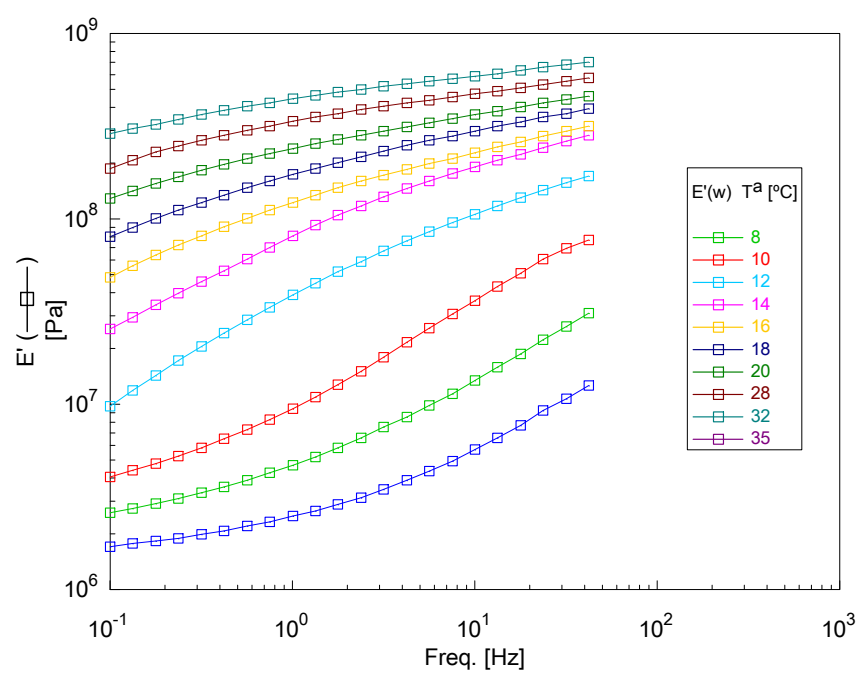

Figure 6. Storage modulus curves at different temperatures for the PVB.

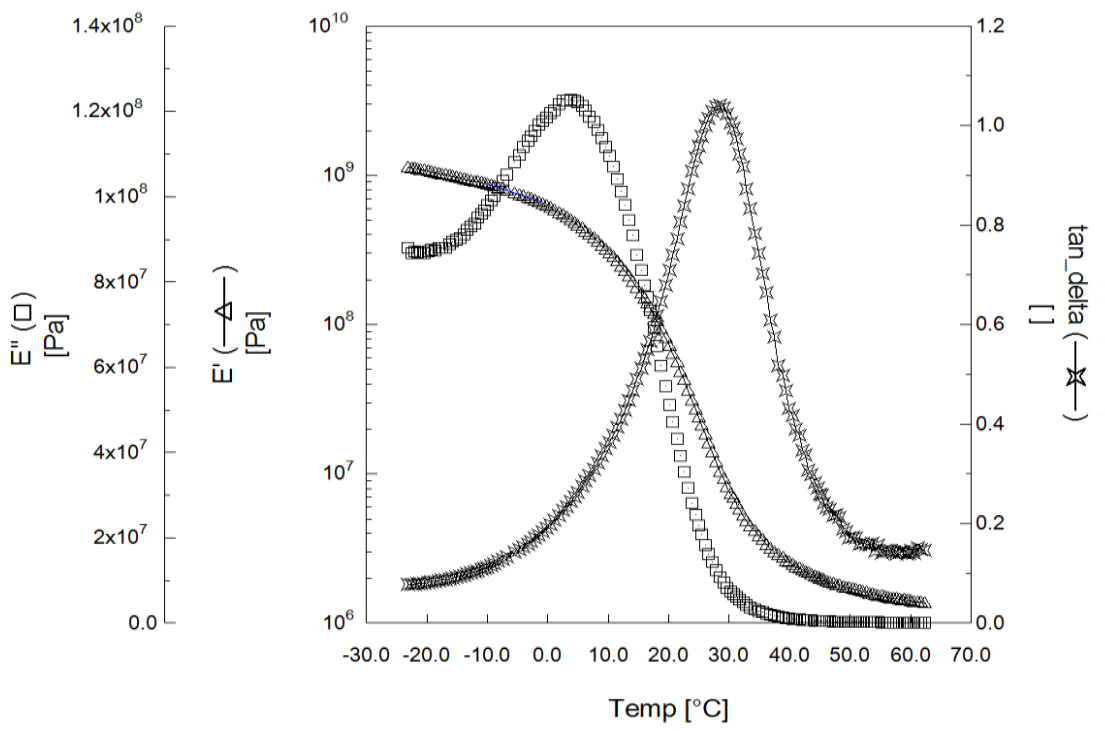

Figure 7. Temperature sweep at $1 \mathrm{~Hz}$ from $-25^{\circ} \mathrm{C}$ to $65^{\circ} \mathrm{C}$ for the PVB.

\section{Analysis of the Results}

\subsection{Glass Transition Temperature}

Although there is not an unique procedure for determining the glass transition temperature [27], according to ASTM D3418-97 [28], $T_{g}$, can be inferred from the maximum peak of the loss modulus $E^{\prime \prime}(\omega)$ obtained with temperature sweep analysis. In this case, $T_{g}$, is approximately at $+8^{\circ} C$ (see Figure 6). 
The initial overlay master curve of the material was obtained by overlapping the individual curves (see Figure 5), that is, each curve was horizontally shifted (only time-shifts were considered) to the reference one using a residual minimization algorithm based on cubic spline interpolation [29]. In Figure 8 , it is shown the overlay master curve when $20^{\circ} \mathrm{C}$ is used as reference temperature together with the experimental shift factors $a_{T}^{\text {exp }}$.

From Figure 8, it can be inferred that the material presents a thermorheological simple behaviour [16], therefore, the technique of time-temperature superposition can be applied for obtaining the master curve of PVB. Once the overlay master curve is obtained, the experimental shift factors, $a_{T}^{\text {exp }}$, for each curve can be estimated (see Figure 8). It can be observed in Figure 8 the shift factors exhibits a change in the tendency when temperature falls from $10^{\circ} \mathrm{C}$. This fact agrees with the breakdown of the WLF TTS model at temperatures lower than the glass transition temperature of the material [23]. The phenomenon can be understood as a reduction of the free volume and mobility in the molecules, so less variation of the material properties with temperature is expected and, consequently, a reduction in the corresponding shift factors should occur [25]. This breakdown of the $a_{T}^{\text {exp }}$ is also in agreement with the glass transition temperature $T_{g}=8^{\circ} \mathrm{C}$, obtained from Figure 7 , and must be taken into account to establish the range of validity of the WLF model. It must be emphasized that fitting all the temperature range (see Figure 8 left) with the WLF model will lead to erroneous constants $C_{1}$ and $C_{2}$ and, consequently, uncertainties and errors when the WLF model is used to shift the master curve of the material. In this way, $10^{\circ} \mathrm{C}$ should be considered as the lower limit of applicability of the WLF model for PVB.
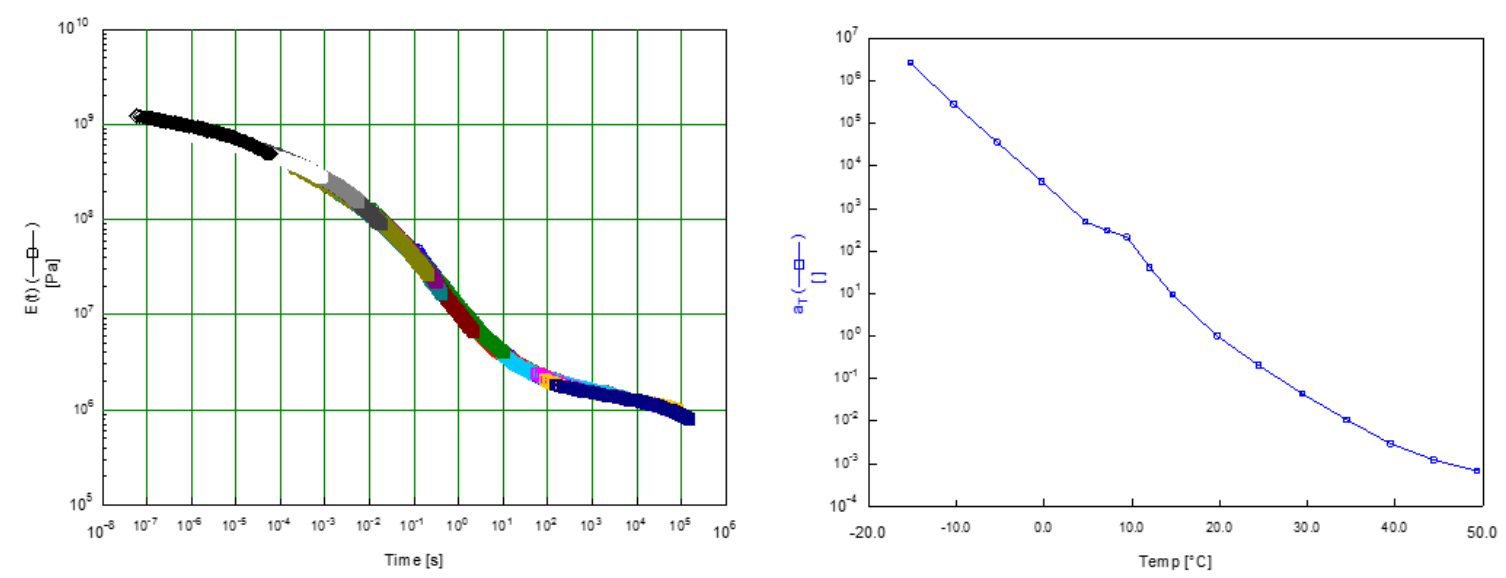

Figure 8. Overlay curve of PVB (left) and experimental $\boldsymbol{a}_{\boldsymbol{T}}^{\text {exp }}$ (right) for a reference temperature of $20^{\circ} \mathrm{C}$. 
Although the WLF fitting process can be carried out taken $T_{g}$ as reference temperature, William, Landel and Ferry recommend to use a temperature $T_{s}$ [23] (see Eq. (6)) in the fitting process. This temperature $T_{s}$ corresponds approximately to the end tail of the viscoelastic behaviour zone.

The WLF model (Eq. (4)) was fitted to the experimental results in the range from $10^{\circ} \mathrm{C}$ to $50^{\circ} \mathrm{C}$ using the shift factors $a_{T}^{\exp }$ shown in Figure 8. These values were obtained considering $T_{0}=T_{S}=50^{\circ} \mathrm{C}$ as reference temperature.

The parameters $C_{1}^{S}=8.9932$ and $C_{2}^{S}=104.76$ are close to the universal constants proposed by WLF: $C_{1}^{S W L F}=8.86$ and $C_{2}^{S W L F}=101.6$, the errors being $1.5 \%$ and $3 \%$ for $C_{1}$ and $C_{2}$, respectively. If the WLF is fitted using $T_{g}$ (in this case $T_{g}=10^{\circ} C$ ) the following constants $C_{1}^{g}=11.208$ and $C_{2}^{g}=$ 41.818 are obtained, that differ slightly from those proposed by WLF when $T_{g}$ is used: $C_{1}^{g W L F}=$ 17.44 and $C_{2}^{g W L F}=51.6$. It has to be noticed that the universal constants proposed by WLF for $T_{g}$ are obtained with an exact shift of $50^{\circ} C$ from $T_{s}$ using Eqs. (5) and (6).

Whereas $T_{s}$ and $T_{g}$ are the reference temperatures recommended to fit the experimental data to the model ( $T_{s}$ being preferable according to [23]), whatever temperature in the range $T_{g}<T<T_{s}$ could be used in the fitting process, but the results obtained will always present less accuracy than the other two cases (see Figure 9). This fact has to be considered in the analysis because, in general, the WFL model for PVB is fitted using a reference temperature of $20^{\circ} \mathrm{C}$ (room temperature) [4, 24] so large errors are being introduced in the PVB mechanical characterization.
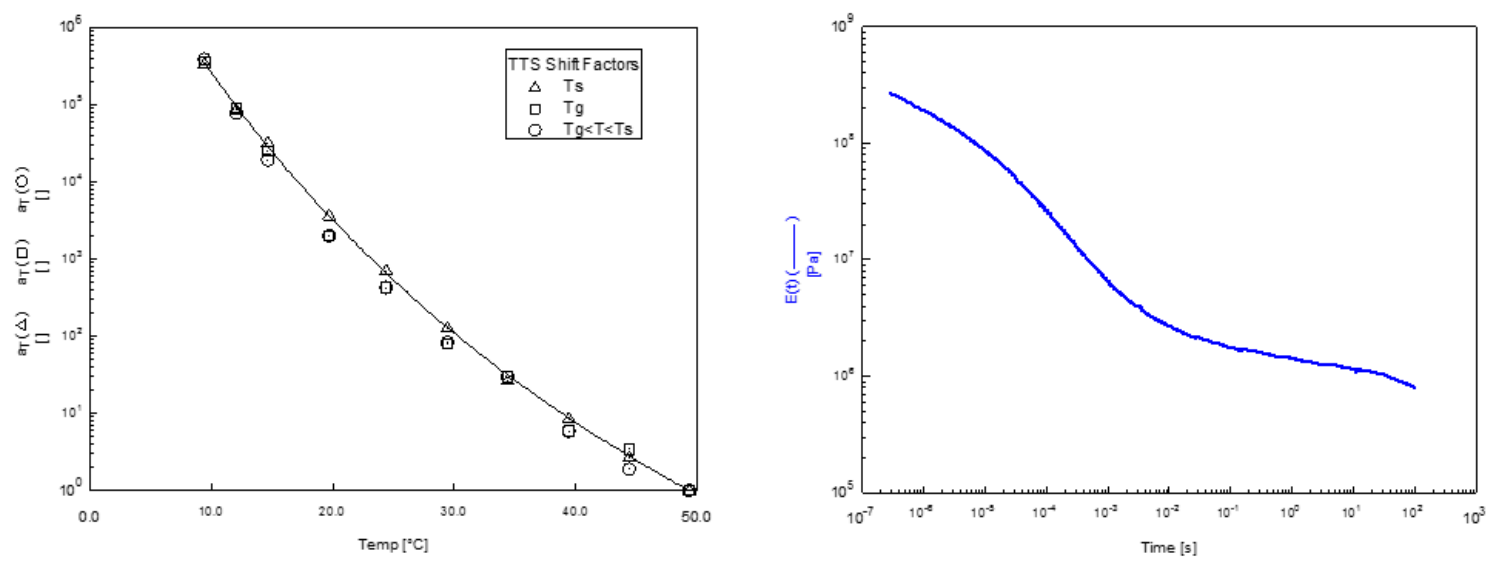

Figure 9. Comparison of the WLF model when $\boldsymbol{T}_{s}, \boldsymbol{T}_{g}$ or a temperature within the range $\boldsymbol{T}_{g}<\boldsymbol{T}<$ $\boldsymbol{T}_{s}$ are used (left) and final master curve of the PVB for $\boldsymbol{T}_{\boldsymbol{s}}=\mathbf{5 0}^{\circ} \boldsymbol{C}$ (right).

Once the WLF is fitted, the master curve of the PVB for reference temperature $T_{S}$ can be constructed using Eq. (4) (see Figure 9). The master curve at another temperature $T_{1}$, within the WLF temperature range $\left(T_{g}<T<T_{s}\right)$, can be directly obtained shifting the master curve at $50^{\circ} \mathrm{C}$ with the corresponding 
$a_{T}$ estimated with Eq. (4) and the constants $C_{1}^{S}$ and $C_{2}^{S}$. The new constants $C_{1}^{1}$ and $C_{2}^{1}$ corresponding to temperature $T_{1}$ can be obtained with Eqs. (4) and (5), respectively. If temperatures lower than $10^{\circ} \mathrm{C}$ must be taken into account, a new TTS model should be used to fit properly the experimental shift factors below this temperature rather than use the $a_{T}$ obtained with the WLF for the glass transition zone. In the case of PVB, the mechanical behaviour or laminated glass below the glass transition temperature can be assimilated to a monolithic glass with a thickness equal to the total thicknesses of the laminated glass elements [5 14], Therefore, the TTS for PVB below $10^{\circ} \mathrm{C}$ has less relevance from a practical point of view. The full viscoelastic model for the PVB will be presented in section 4.4 .

\subsection{TTS Application for the Complex modulus master curve of PVB}

As a second step, the maste curve for the dynamic complex modulus (frequency domain) of the PVB is obtained. The higher experimental temperature is $35^{\circ}$ so in the WLF fitting process, this temperature was considered as reference. Although this temperature is below the recommended one, $T_{s} \approx T_{g}+50^{\circ} \mathrm{C}$, the lower storage values of the experimental curve at $35^{\circ} \mathrm{C}$ (see Figure 6) are close to the minimum value of the material modulus, i.e. close to the low-frequency tail of the master curve and, therefore, it can be considered adequate. The overlay curve for the complex moduli at $35^{\circ} \mathrm{C}$ is presented in Figure 9 where the storage modulus $E^{\prime}(\omega)$ (real part of the complex modulus) and the ratio $\tan \delta=E^{\prime \prime}(\omega) / E^{\prime}(\omega)$, being $E^{\prime \prime}(\omega)$ the loss modulus (imaginary part of the complex modulus), are shown.

The constants obtained for the WLF model at the reference temperature are: $C_{1}^{35}=9.7240$ and $C_{2}^{35}=$ 97.0580. Using Eqs. (5) and (6) these constants can be shifted to $50^{\circ} C$, which corresponds with the value of $T_{S}$ used for the WLF model in the relaxation master curve, being $C_{1}^{50}=8.4128$ and $C_{2}^{50}=$ 112.0580. If these values $\left(C_{1}^{50}\right.$ and $\left.C_{2}^{50}\right)$ are compared with those previously fitted for the relaxation modulus master curve $\left(C_{1}^{S}=8.9932\right.$ and $\left.C_{2}^{S}=104.76\right)$, the errors are less than $6.5 \%$ for both constants. If they are compared with the universal constants proposed for WLF at $T_{s}$, the errors are approximately $5 \%$ and $10 \%$ for $C_{1}$ and $C_{2}$, respectively, which are slightly higher than those obtained in the relaxation master curve. However, large errors are expected because the reference temperature $T_{0}=35^{\circ} \mathrm{C}$ consider to fit the complex modulus is lower to the recommended $T_{S}$ [23]. 


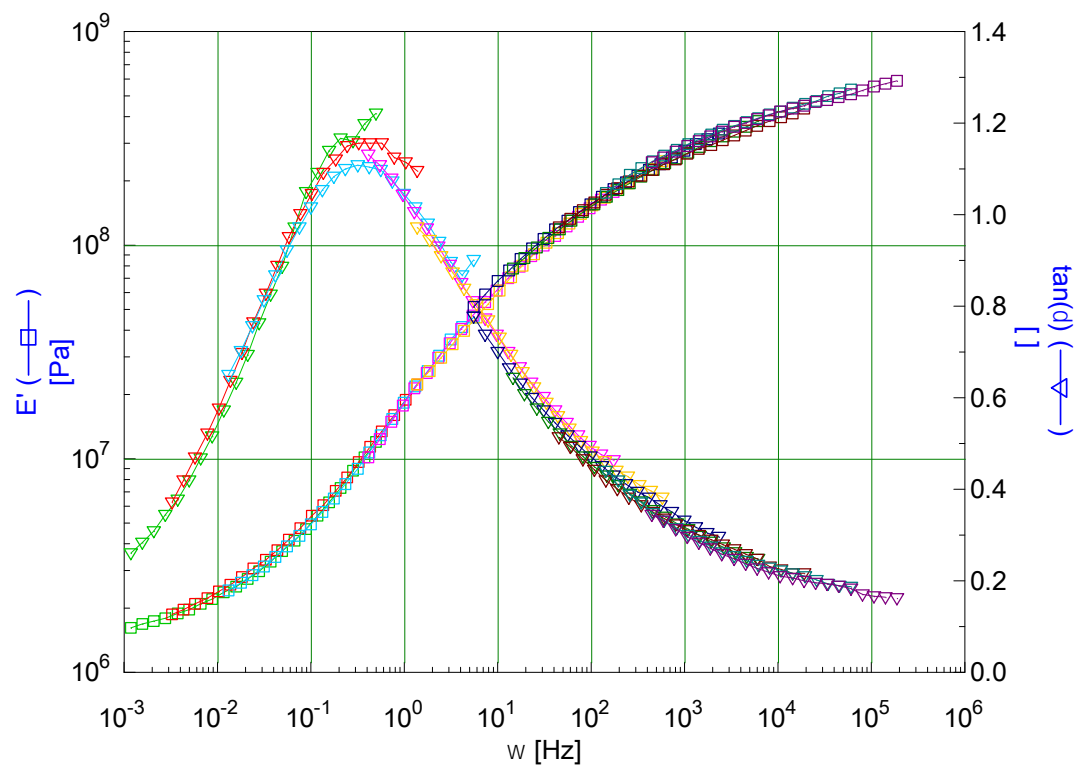

Figure 10. Overlay complex modulus curve for the PVB at $35^{\circ} \mathrm{C}$.

\subsection{PVB viscoelastic model}

After fitting the WLF model to the experimental data, the mastercuve of both relaxation and complex modulus can be constructed. Although the master curves can be obtained for the complete time window of the overlay curves (see Figure 8 and Figure 10), the WLF can be only used to shift both relaxation and complex moduli in the validity range i.e. from $10^{\circ} \mathrm{C}$ to $50^{\circ} \mathrm{C}$.

A generalized Maxwell model $[15,16]$ was used to model the viscoelastic behaviour of the PVB. The model consist of several individual Maxwell models combined in parallel (see Figure 11).

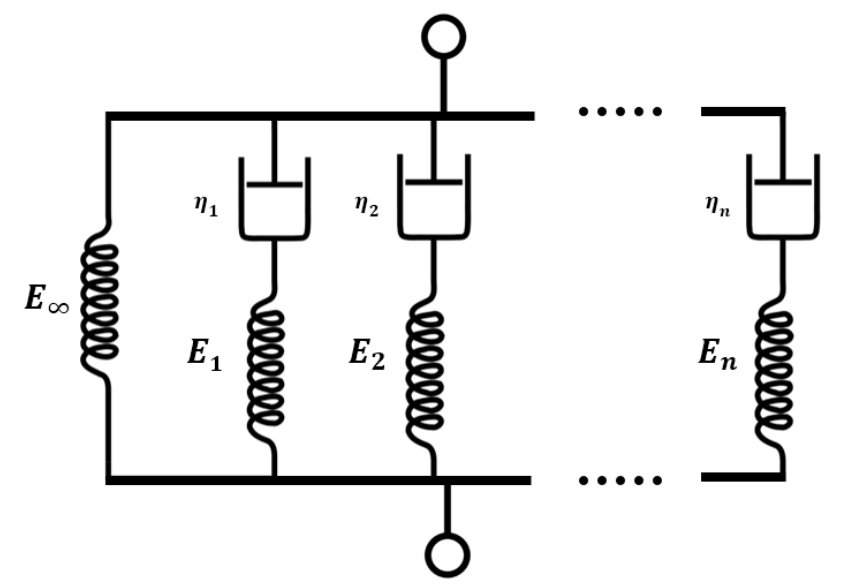

Figure 11. Generalized Maxwell model.

If the generalized Maxwell model is represented by a Prony's series [26], the relaxation Young modulus can be expressed as: 


$$
\mathrm{E}(\mathrm{t})=\mathrm{E}_{0}\left[1-\sum_{\mathrm{i}=1}^{\mathrm{n}_{\mathrm{t}}} \mathrm{e}_{\mathrm{i}}\left(1-\exp \left(-\frac{\mathrm{t}}{\tau_{\mathrm{i}}}\right)\right)\right]
$$

where $E_{0}$ is the instantaneous modulus of the material, $n_{t}$ is the number of Maxwell terms used in the model and $\left(e_{i}, \tau_{i}\right)$ are the Prony coefficients. The experimental master curve for a reference temperature $T=20^{\circ} \mathrm{C}$ and the viscoelastic fitted model using 13 terms in the Prony series (R-square 0.99943 ) are presented in Figure 10. The master curve at $20^{\circ} \mathrm{C}$ was obtained by shifting the master curve at $T_{s}=50^{\circ} \mathrm{C}$ using the WLF model and the constants calculated with Eqs. (5) and (6), i.e. $C_{1 R}^{20}=12.6010$ and $C_{2 R}^{20}=74.7600$. The Prony coefficients for the viscoelastic model of the PVB are presented in Table 1.

Table 1. Prony series coefficients for PVB

\begin{tabular}{cc}
\hline \multicolumn{1}{c}{$e_{i}$} & $\tau_{i}[\mathrm{~s}]$ \\
\hline $2.342151953 \mathrm{E}-01$ & $2.36600000000000 \mathrm{E}-07$ \\
$2.137793134 \mathrm{E}-01$ & $2.26430000000000 \mathrm{E}-06$ \\
$1.745500419 \mathrm{E}-01$ & $2.16668000000000 \mathrm{E}-05$ \\
$1.195345045 \mathrm{E}-01$ & $2.07327300000000 \mathrm{E}-04$ \\
$1.362133454 \mathrm{E}-01$ & $1.98389580000000 \mathrm{E}-03$ \\
$6.840656310 \mathrm{E}-02$ & $1.89837195000000 \mathrm{E}-02$ \\
$4.143944180 \mathrm{E}-02$ & $1.81653498300000 \mathrm{E}-01$ \\
$7.251952800 \mathrm{E}-03$ & $1.73822593210000 \mathrm{E}+00$ \\
$2.825459600 \mathrm{E}-03$ & $1.66329270788000 \mathrm{E}+01$ \\
$2.712854000 \mathrm{E}-04$ & $1.59158978189400 \mathrm{E}+02$ \\
$4.293523000 \mathrm{E}-04$ & $1.52297789909670 \mathrm{E}+03$ \\
$9.804730000 \mathrm{E}-05$ & $1.45732380763177 \mathrm{E}+04$ \\
$5.274937000 \mathrm{E}-04$ & $1.39449999999999 \mathrm{E}+05$ \\
\hline
\end{tabular}

Once the relaxation modulus of the material is known in terms of Prony coefficients, $\left(e_{\mathrm{i}}, \tau_{\mathrm{i}}\right)$, it can be used to obtain the components of the complex modulus by interconversion techniques, i.e. the storage modulus $E^{\prime}(\omega)$ and the loss modulus $E^{\prime \prime}(\omega)[31,32]$ are given by:

$$
\begin{aligned}
& \mathrm{E}^{\prime}(\omega)=\mathrm{E}_{\infty}+\sum_{\mathrm{i}=1}^{\mathrm{n}} \frac{\tau_{\mathrm{i}}^{2} \omega^{2} \mathrm{e}_{\mathrm{i}}}{\tau_{\mathrm{i}}^{2} \omega^{2}+1} \\
& \mathrm{E}^{\prime \prime}(\omega)=\sum_{\mathrm{i}=1}^{\mathrm{n}} \frac{\tau_{\mathrm{i}}^{2} \omega^{2} \mathrm{e}_{\mathrm{i}}}{\tau_{\mathrm{i}}^{2} \omega^{2}+1}
\end{aligned}
$$

The complex modulus components of the PVB at $T=20^{\circ} \mathrm{C}$, obtained from the relaxation Prony coefficients using Eqs. (9) and (10), are presented in Figure 12 together with the experimental complex modulus master curve. The experimental complex modulus master curve has been shifted 
from $35^{\circ} \mathrm{C}$ to $20^{\circ} \mathrm{C}$ using the same WLF constants as those obtained by fitting the relaxation modulus. The WLF constants obtained using Eqs. (5) and (6) for $20^{\circ} C$ were: $C_{1 C}^{20}=11.4885$ and $C_{2 C}^{20}=82.0580$, resulting in an error of $9 \%$ when compared with those obtained from the WLF of the relaxation master curve.

From Figure 12, it is inferred than a good accuracy is also obtained using interconversion techniques (errors less than 10\%), so that the WLF model proposed can be considered adequate to represent the PVB mechanical behaviour in both time (relaxation modulus) and frequency (complex modulus) domains. On the other hand, similar constants $C_{1}$ and $C_{2}$ of the WLF model were obtained for both relaxation and complex moduli master curves, confirming that the WLF can be applied successfully to shift the master curve of the PVB at different temperatures. This fact is shown in Figure 10 where both predicted and experimental curves are shifted from $50^{\circ} \mathrm{C}$ and $35^{\circ} \mathrm{C}$, respectively, to a reference temperature $T_{0}=20^{\circ} \mathrm{C}$.

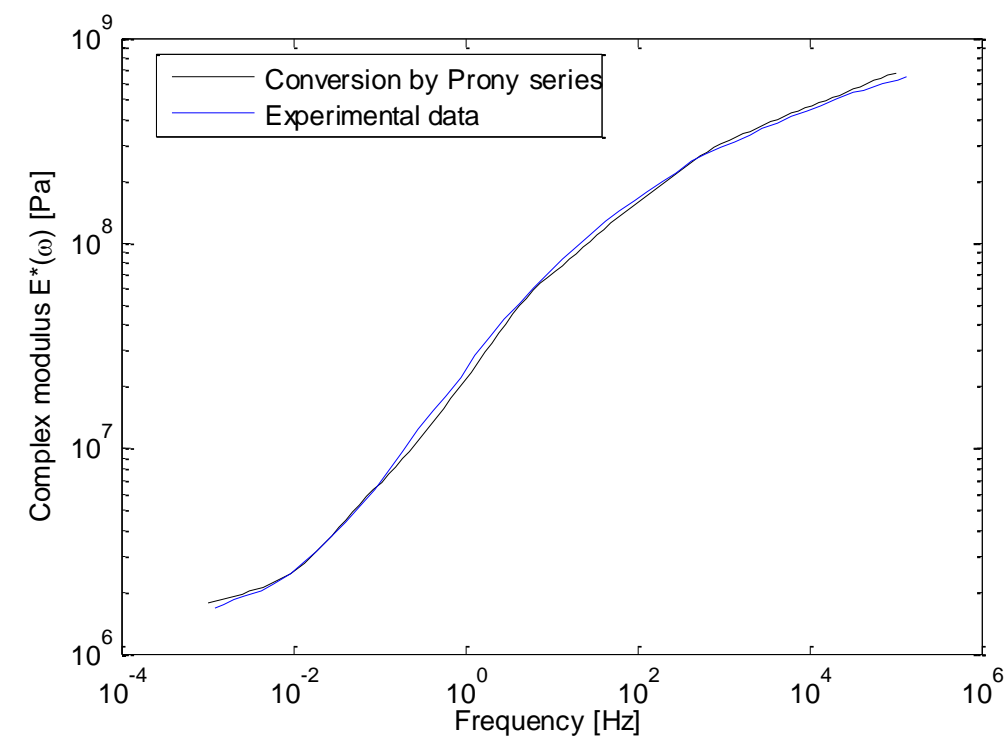

Figure 12. Complex modulus of the PVB obtained by interconversion from the relaxation Prony coefficients at $20^{\circ} \mathrm{C}$.

\section{Practical application: prediction of laminated glass elements behaviour}

In this section, the mechanical properties of the PVB obtained in section 4.4 were used to predict the response of laminated glass elements under static and dynamic loadings. Both analytical models $[5,10,14,33,34]$ as well as numerical models, i.e. by the finite element method [35], can be used for this purpose but in this paper a finite element model was assembled in ABAQUS considering the Prony series coefficients presented in Table 1 and the WLF model constants $C_{1}$ and $C_{2}$ indicated in section 4.4 


\subsection{Laminated glass plate under static loading}

A laminated glass plate pinned supported at the four corners with 4 wood balls (diameter of $50 \mathrm{~mm}$ ) , dimensions $a=1.4 \mathrm{~m}, \quad b=1 \mathrm{~m}$ and thicknesses $h_{\text {glass }}=8 \mathrm{~mm}$ for the glass layers and $h_{P V B}=$ $0.76 \mathrm{~mm}$ for the PVB layer, respectively, was statically tested under an uniformly distributed loading of $920 \mathrm{~N} / \mathrm{m}^{2}$. The experiment was conducted at $21.5^{\circ} \mathrm{C}$ (room temperature). The displacement of the central point of the plate was measured using a laser sensor (AR700-12) for approximately 26 hours with a NI-CDAQ system (NI9239).

In order to validate the mechanical properties of the PVB, a 3D finite element model was assembled in ABAQUS. 3D linear shell continuum elements (SC8R) were used for the glass layers [36] whereas the PVB layers were meshed with 3D linear hexahedral elements (C3D8R). This meshing technique has been demonstrated to be adequate to reproduce the laminated glass behaviour with a relatively low computational time [35]. A detail of the mesh is shown in Figure 13. The elastic properties used for both glass and PVB are presented in Table 2. The mechanical behaviour of the PVB interlayers was considered viscoelastic in terms of Prony series whose coefficients are shown in Table 1, whereas the WLF constants were $C_{1 R}^{20}=12.6010$ and $C_{2 R}^{20}=74.7600$.

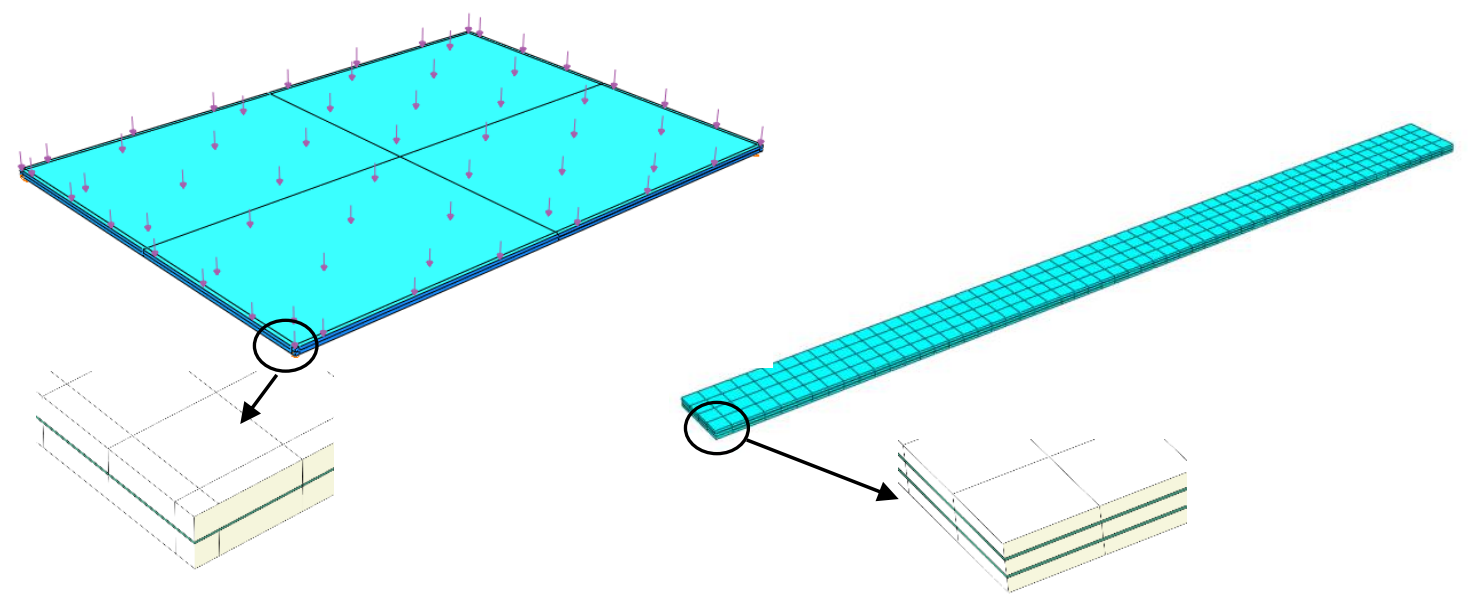

Figure 13. Finite element models for the laminated glass plate and beam.

Table 2. Mechanical properties of glass and PVB.

\begin{tabular}{cccccc}
\hline$E_{\text {glass }}[\mathrm{GPa}]$ & $v_{\text {glass }}$ & $\rho_{\text {glass }}\left[\mathrm{kg} / \mathrm{m}^{3}\right]$ & $E_{0_{P V B}}[\mathrm{GPa}]$ & $v_{P V B}$ & $\rho_{P V B}\left[\mathrm{~kg} / \mathrm{m}^{3}\right]$ \\
\hline 72 & 0.22 & 2500 & 1.2403 & 0.40 & 1046 \\
\hline
\end{tabular}


The experimental and numerical displacement at the central point of the plate are presented in Figure 14. It can be observed in the figure that a good correlation exists between the experimental and the simulated displacement, the larger error being less than $1.75 \%$.

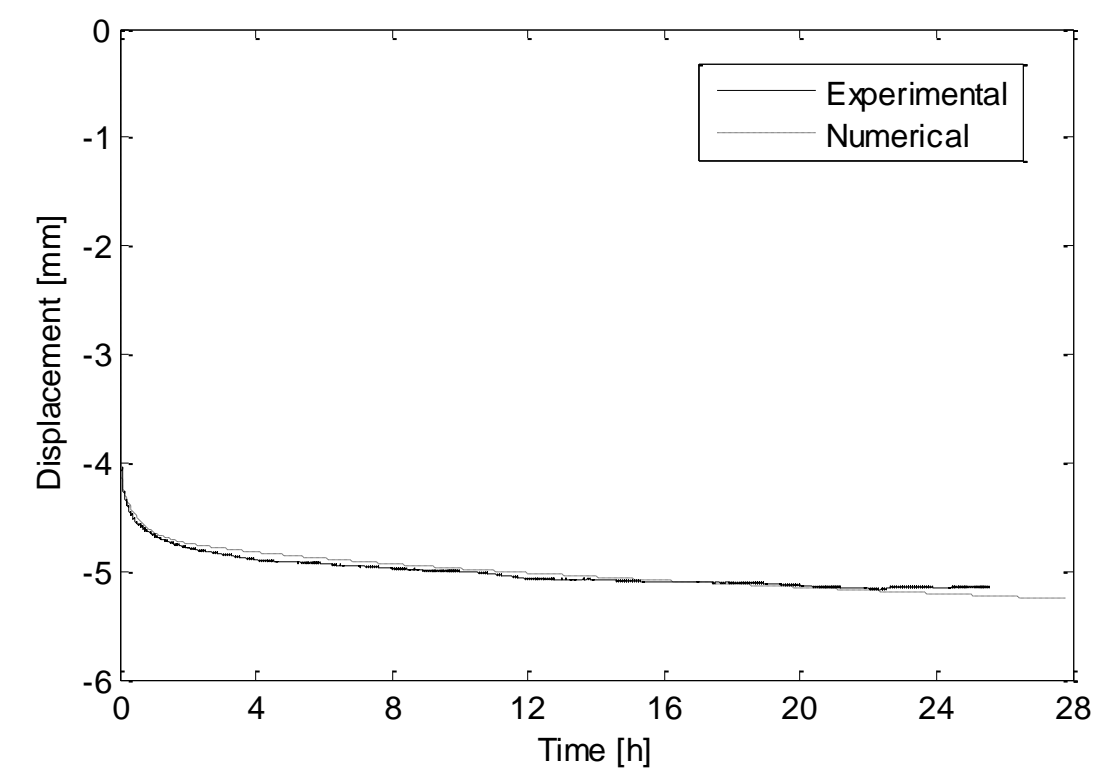

Figure 14. Displacement of central point of the laminated glass plate.

\subsection{Multilayered laminated glass beam: dynamic behaviour}

A multilayered laminated glass beam $1000 \mathrm{~mm}$ long and $100 \mathrm{~mm}$ wide thicknesses $h_{\text {glass }}=4 \mathrm{~mm}$ (3 layers) and $h_{P V B}=0.38 \mathrm{~mm}$ (2 layers) was used in the experiments. The beam was tested under free-free conditions using operational modal analysis [37]. Seven accelerometers (B\&K: $100 \mathrm{mv} / \mathrm{g}$ ) uniformly distributed along the beam were used to measure the responses and recorded with a NICDAQ system (NI9234). The beam was excited applying small hits along the beam random in time and space with an impact hammer and the responses were recorded for approximately 4 minutes using a sampling frequency of $1000 \mathrm{~Hz}$. The modal tests were performed in a climate chamber at 20, 25 and $30{ }^{\circ} \mathrm{C}$, respectively. The modal parameters of the beam were estimate using the Frequency Domain Decomposition technique (EFDD) [37].

A 3D numerical model of the beam was also assembled in ABQUS meshing the glass layers with 3D linear shell continuum elements (SC8R) [35] whereas the PVB layers were meshed with 3D linear hexahedral elements (C3D8R). With respect to the mechanical behaviour, the same mechanical properties as those used in the plate were considered for the glass and the PVB interlayers (see Figure 13). In order to obtain the numerical modal parameters of the beam, the frequency response function (FRF) was obtained from a sweep sine analysis (linear frequency analysis) [35] subjecting the specimen to a uniform loading with a magnitude of $1 \mathrm{~N}$ for all the frequency range considered in the 
simulations. Then, the natural frequencies were estimated by the peak picking method [38, 39] whereas the damping ratios were obtained by the logarithmic decrement technique $[38,39]$.

The numerical natural frequencies and loss factors are presented in Table 3, together with those obtained experimentally. It is assumed that the damping ratios and the loss factors are related by $\eta \approx$ $2 \zeta[40]$.

With respect to the natural frequencies, the error between the experimental and the numerical values was consistently less than $2.5 \%$. On the other hand, large discrepancies were encountered in the loss factors, being the errors about $20 \%$ for the first mode at $T=30^{\circ} \mathrm{C}$. It has to be noticed that the uncertainty bounds of damping ratios (or loss factors) are usually much higher than those of the natural frequencies [41].

Table 3. Frequencies and damping ratios for the multilayered laminated glass beam at different temperatures.

\begin{tabular}{|c|c|c|c|c|c|c|c|}
\hline \multirow{2}{*}{$\mathrm{T}^{\mathrm{a}}$} & \multirow{2}{*}{ Mode } & \multicolumn{2}{|c|}{ Experimental } & \multicolumn{2}{|c|}{ Numerical } & \multicolumn{2}{|c|}{ Error } \\
\hline & & Freq. [Hz] & $\eta[\%]$ & Freq. [Hz] & $\eta[\%]$ & Freq. [\%] & $\eta[\%]$ \\
\hline \multirow{4}{*}{$20^{\circ} \mathrm{C}$} & 1 & 36.14 & 1.18 & 36.58 & 1.26 & 1.19 & 7.16 \\
\hline & 2 & 98.28 & 2.40 & 99.35 & 2.76 & 1.08 & 12.79 \\
\hline & 3 & 188.94 & 3.24 & 191.18 & 3.72 & 1.17 & 12.78 \\
\hline & 4 & 306.13 & 4.40 & 308.58 & 4.84 & 0.79 & 9.00 \\
\hline \multirow{4}{*}{$25^{\circ} \mathrm{C}$} & 1 & 35.95 & 2.32 & 36.39 & 2.02 & 1.21 & 14.91 \\
\hline & 2 & 96.56 & 4.22 & 97.87 & 4.30 & 1.35 & 2.30 \\
\hline & 3 & 185.52 & 5.84 & 186.80 & 7.12 & 0.69 & 18.19 \\
\hline & 4 & 297.53 & 8.74 & 300.61 & 8.82 & 1.03 & 1.10 \\
\hline \multirow{4}{*}{$30^{\circ} \mathrm{C}$} & 1 & 35.40 & 5.66 & 35.95 & 4.44 & 1.54 & 21.55 \\
\hline & 2 & 93.32 & 7.88 & 95.56 & 7.96 & 2.34 & 0.94 \\
\hline & 3 & 175.72 & 10.82 & 180.02 & 11.46 & 2.39 & 5.69 \\
\hline & 4 & --- & --- & 283.86 & 13.96 & --- & --- \\
\hline
\end{tabular}

\section{Conclusions}

In this paper, the viscoelastic behaviour of the PVB and the range of application of the WLF-TTS model have been analyzed. The most accurate results for the WLF model constants $C_{1}$ and $C_{2}$ were obtained when $T_{S}$ is considered as reference temperature, being the results for the PVB in good agreement with the general universal constants proposed by WLF [18].

The WLF model was applied to determine both relaxation $E(t)$ and complex $E^{*}(\omega)$ moduli of the PVB from the experimental tests conducted at different temperatures. The WLF model for the 
complex modulus leads to approximately the same constants $C_{1}$ and $C_{2}$ (error less than a 6.5\%) than those obtained from the relaxation modulus $E(t)$.

The breakdown of the proposed WLF model for the PVB is in good agreement with the beginning of the Glass transition zone for the material $\left(T_{g}^{P V B}: 8-10^{\circ} C\right)$. Therefore, the change in the slope of the experimental shift factors $a_{T}$ is a good indicator to establish the temperature limits of the WLF model. For the standard PVB characterized in this work, the limitation of the proposed WLF model is in the range from 10 to $50^{\circ} \mathrm{C}$.

The experimental viscoelastic relaxation $E(t)$ modulus of the PVB was fitted to a generalized Maxwell model, which was used together with the WLF constants $C_{1}$ and $C_{2}$ to predict numerically the static behaviour of a laminated glass plate and the dynamic behaviour of a multi-layered laminated glass beam.

The errors between the numerical static deflection of the plate and that measured during the experiments were less than $1.75 \%$. With respect to modal parameters predicted the errors were less than $2.5 \%$ for the natural frequencies whereas the loss factors were predicted with a maximum error of $22 \%$, which are of the same order as those by the authors in laminated glass elements [5]. These results demonstrate that the mechanical properties of the PVB obtained in this paper represent adequately the 1 viscoelastic behaviour of the material.

\section{Acknowledgements}

The authors gratefully acknowledge the financial support of the Asturian Regional Research through the Severo Ochoa Pre-doctoral Grants, as well as through the BIA2011-28959, BIA2014-53774-R and DPI2016-80389-C2-2-R research projects.

\section{References}

[1] Behr, R.A., Minor, J.E., Norville, H.S., Structural behavior of architectural laminated glass. 119 (1) 202-222 (1993).

[2] Haldimann, M., Luible, A., Overend, M. Structural use of glass. Structural engineering documents (10). IABSE, (2008).

[3] Foraboschi., P., Experimental characterization of non-linear behavior of monolithic glass. International Journal of Non-Linear Mechanics, 67, 352-370 (2014). 
[4] Benninson, S., M.HX, Q. and Davies, P., High-performance laminated glass for structurally efficient glazing. Innovative Light-weight Structures and Sustainable Facades, Hong Kong, May, 2008.

[5] López-Aenlle, M., Pelayo, F. Dynamic effective thickness in laminated-glass beams and plates. Composite: Part B, 67, 332-347, (2014).

[6] Baraldi, D., Cecchi, A., Foraboschi, P. Broken tempered laminated glass: Non-linear discrete element modeling. Composite Structures, 140, 278-295 (2016).

[7] P. Foraboschi, P. Optimal design of glass plates loaded transversally. Materials and Design, 62, 443-458 (2014).

[8] Koutsawa, Y., Daya, E.M., Static and free vibration analysis of laminated glass beam on vis scoelastic supports, International journal of solids and structures, 44, pp. 8735-8750 (2007).

[9] Galuppi, L., Royer-Carfagni, G.F., Laminated beams with viscoelastic interlayer, Journal of solids and structures, 49(18), 2637-2645 (2012).

[10 ] Foraboschi, P., Three-layered sandwich plate: Exact mathematical model. Composites Part BEngineering, 245, 1601-1612 (2013).

[11] Foraboschi, P., Hybrid Laminated-Glass plate: Design and assessment. Composite Structures, 106, 250-263 (2013).

[12] Aenlle, M.L., Pelayo, F., Frequency response of laminated glass elements: analytical modeling and effective thickness. Applied Mechanics Reviews, 65(2):020802-020802-13 (2013).

[13] Tschoegl, N.W.. The Phenomenological theory of linear viscoelastic behaviour. SpringerVerlag, Berlin (1989).

[14] Lakes, R., Viscoelastic solids. CRC Press, New York, (2009).

[15] Phan-Thien, N. On the time-temperature superposition principle of dilute polymer liquids, Journal of rheology. 23 (4), 451-456 (1979).

[16] Tobolsky, A.V., Properties and structure of polymers, Wiley, New York (1967).

[17] Dealy, J., Plazek D., Time-temperature superposition - A users guide. Rheology bulletin, 78(2), 16-31 (2009). 
[18] Honerkamp, J., Weese, J., A note on estimating master curves, Rheologica Acta. 32(1), 57-64, (1993) doi: 10.1007/BF00396677.

[19] Sopade, P.A., Halley, P., Bhandari, B., D'arcy B., Doebler, C. and Caffin, N., Application of the Williams-Landel-Ferry model to the viscosity-temperature relationship of Australian honeys. Journal of food engineering, 56, 67-75 (2002)

[20] Povolo, F., Fontelos, M., General function with scaling properties and the time-temperature superposition. Il nuevo cimento. 13(12), 1513-1525 (1991)

[21] Williams, M.L., Landel, R.F., Ferry, J., The temperature dependence of relaxation mechanisms in amorphous polymers and other glass-forming liquids. Journal of the American chemical society, 77, 8701 (1955).

[22] Bohan, L., Xu, J., Yibing, Li., Constitutive Investigation on Viscoelastic of Polyvinyl Butyral: Experiments Based on Dynamic Mechanical Analysis. Advances in Materials Science and Engineering. ID: 794568 (2014).

[23] Ferry, J.D. Viscoelastic properties of polymers. John Wiley \& Sons, New York (1980).

[24] ASTM D5026-15. Standard Test Method for Plastics: Dynamic Mechanical Properties: In Tension (2015).

[25] Rongzhi Li,. Time-temperature superposition method for glass transition temperature of plastic materials. Materials science and engineering. 278(1-2), 36-45 (1999).

[26] ASTM D3418-15 Standard test method for transition temperatures and enthalpies of fusion and crystallization of polymers by differential scanning calorimetry (2015).

[27] TA Orchestrator User Manual (v7.2.0.4). TA Instruments - Waters LLC, New Castle (2008).

[28] Galuppi L., Royer-Carfagni G.F., Effective thickness of laminated glass beams: new expression via a variational approach. Engineering Structures; 44, 53-67 (2012).

[29] Tzikang, C., Determining a prony series for a viscoelastic material from time varying strain data. NASA Langley Technical Report Server (2000).

[30] Emri, I., Von Bernstorff, B.S., Cvelbar, R., Nikonov, A., Re-examination of the approximate methods for interconversion between frequency-and time-dependent material functions. Journal of non-Newtonian fluid mechanics, 129, 75-84 (2005). 
[31] Park, S.W., Schapery, R.A., 1999. Methods of interconversion between linear viscoelastic material functions. Part I-a numerical method based on Prony series. International journal of solids and structures. 36, 1653-1675 (1999). doi:10.1016/S0020-7683(98)00055-9.

[32] Focacci, F., Foraboschi, P., De Stefano, M. Composite beam generally connected: Analytical model. Composite Structures, 1237-1248 (2015).

[33] Foraboschi, P., Analytical model for laminated-glass plate. Composites Part B: Engineering, 43(5), 2094-2106 (2012).

[34] Foraboschi, P., Behavior and failure strength of laminated glass beams. Journal of Engineering Mechanics, 133(12) 1290-1301 (2007).

[35] Abaqus User's Manual, Dassault Systémes Simulia Corp., Providence, Rhode Island, USA (2012).

[36] Fröling M., Persson K., Computational methods for laminated glass. Journal of engineering mechanics, 10.1061/(ASCE)EM.1943-7889.0000527, 780-790 (2013).

[37] Brincker, R., Ventura, C., Introduction to operational modal analysis. Wiley (2015).

[38] Ewins D.J., Modal testing: theory, practice and application (2nd Ed.). John Wiley \& Sons Ltd. Hertford (2000).

[39] Maia M.M., Silva M.M. et al. Theoretical and experimental modal analysis. Research Studies Press and John Wiley \& Sons Ltd., Hertford (2007).

[40] Jones D.I.G., Handbook of viscoelastic vibration damping. John Wiley \& Sons, Ltd., New York (2001).

[41] Gersch W., On the Achievable accuracy of structural system parameter estimates. Journal of sound and vibration, 34(1), 63-79 (1974). 
Figure Captions:

Figure 1. General steps of the time-temperature superposition method.

Figure 2. Schematic of the master curve creation process

Figure 3. Example of relaxation modulus master curves at different temperatures

Figure 4. DMTA (RSA3. TA. Instruments) and tensile fixtures used in the experiments.

Figure 5. Relaxation curves at different temperatures for the PVB.

Figure 6. Storage modulus curves at different temperatures for the PVB.

Figure 7. Temperature sweep at $1 \mathrm{~Hz}$ from $-25^{\circ} \mathrm{C}$ to $65^{\circ} \mathrm{C}$ for the PVB.

Figure 8. Overlay curve of PVB (left) and experimental $a_{T}^{\text {exp }}$ (right) for a reference temperature of $20^{\circ} \mathrm{C}$.

Figure 9. Comparison of the WLF model when $T s, T g$ or a temperature within the range $T g<T<$ $T s$ are used (left) and final master curve of the PVB for $T s=50^{\circ} \mathrm{C}$ (right).

Figure 10. Overlay complex modulus curve for the PVB at $35^{\circ} \mathrm{C}$.

Figure 11. Generalized Maxwell model.

Figure 12. Complex modulus of the PVB obtained by interconversion from the relaxation Prony coefficients at $20^{\circ} \mathrm{C}$.

Figure 13. Finite element models for the laminated glass plate and beam.

Figure 14. Displacement of central point of the laminated glass plate. 